\title{
Comparison of self-reported professional competency across pharmacy education programs: a survey of Thai pharmacy graduates enrolled in the public service program
}

\author{
This article was published in the following Dove Press journal: \\ Advances in Medical Education and Practice \\ 4 October 2014 \\ Number of times this article has been viewed
}

\author{
Nithima Sumpradit ${ }^{1,2}$ \\ Siritree Suttajit ${ }^{3}$ \\ Saowalak Hunnangkul ${ }^{4}$ \\ Thunthita Wisaijohn' \\ Weerasak Putthasri' \\ 'International Health Policy \\ Program, Ministry of Public Health, \\ Nonthaburi, Thailand; ${ }^{2}$ Food and Drug \\ Administration, Ministry of Public \\ Health, Nonthaburi, Thailand; ${ }^{3}$ Faculty \\ of Pharmacy, Chiang Mai University, \\ Chiang Mai, Thailand; ${ }^{4}$ Faculty of \\ Medicine Siriraj Hospital, Mahidol \\ University, Bangkok, Thailand
}

\begin{abstract}
Introduction: Thai pharmacy education consists of two undergraduate programs, a 5-year Bachelor of Science in Pharmacy (BScPsci and BScPcare) degree and a 6-year Doctor of Pharmacy (Pharm D). Pharmacy students who wish to serve in the public sector need to enroll in the public service program. This study aims to compare the perception of professional competency among new pharmacy graduates from the three different pharmacy programs available in 2013 who enrolled in the public service program.
\end{abstract}

Methods: A cross-sectional survey was conducted among new pharmacy graduates in 2013 using a self-administered, structured, close-ended questionnaire. The questionnaire consisted of respondents' characteristics and perception of professional competencies. The competency questions consisted of 13 items with a 5-point scale. Data collection was conducted during Thailand's annual health professional meeting on April 2, 2013 for workplace selection of pharmacy graduates.

Results: A total of 266 new pharmacy graduates responded to the questionnaire (response rate $49.6 \%$ ). There were no significant differences in sex and admission modes across the three pharmacy programs. Pharm D graduates reported highest competency in acute care services, medication reconciliation services, and primary care services among the other two programs. $\mathrm{BScPsci}$ graduates reported more competence in consumer health protection and herbal and alternative medicines than BScPcare graduates. There were significant differences in three competency domains: patient care, consumer protection and community health services, and drug review and information, but no significant differences in the health administration and communication domain among three pharmacy programs.

Conclusion: Despite a complete change into a 6-year Pharm D program in 2014, pharmacy education in Thailand should continue evolving to be responsive to the needs of the health system. An annual survey of new pharmacy graduates should be continued, to monitor changes of professional competency across different program tracks and other factors which may influence their contribution to the health service system. Likewise, a longitudinal monitoring of their competencies in the graduate cohort should be conducted.

Keywords: pharmacy education, professional competency, pharmacy graduate, Doctor of Pharmacy, Thailand

\section{Introduction}

Pharmacists play vital roles in health-care delivery systems, as they are highly accessible among all health-care workers ${ }^{1}$ and provide a wide range of services ranging from manufacturing and regulating medicines, distributing and dispensing medicines, to providing medicine information and pharmaceutical care services. ${ }^{1,2}$ They also serve
Cumpradit International Health Policy Program, Ministry of Public Health,

Nonthaburi I I000, Thailand

Tel +6625907165

Fax +66 25902385

Email nithima@ihpp.thaigov.net submit your manuscript | www.dovepress.com

Dovepress

http://dx.doi.org//0.2147/AMEP.S67391
Advances in Medical Education and Practice 2014:5 347-357 
as regulators and policy makers to control, manage, and supply quality medicines to their nations; and as educators and researchers for pharmacy education and health-related research areas. ${ }^{3}$

The variety of roles for pharmacists creates challenges for pharmacy education, as it needs to adapt its curricula to suit changes in health systems. Starting with a 3-year program in 1914, pharmacy education has evolved to a 4-year certificate's degree program and then to a 5-year bachelor's degree program focused on a variety of subjects that supported pharmacists working in various settings, such as pharmaceutical production, hospitals, community pharmacies, and pharmaceutical regulatory affairs. In 1998, a 6-year Doctor of Pharmacy (Pharm D) program was introduced in Thailand which focused on pharmaceutical care services. ${ }^{2,3}$ Key factors influencing this transition toward a 6-year Pharm D program include, but were not limited to, a limited demand of pharmacists in local pharmaceutical production, a great demand of pharmacists in patient care areas, ${ }^{3}$ and a paradigm shift of pharmacy profession in the USA toward pharmaceutical care. ${ }^{4}$ This paradigm supported a philosophical shift towards a standard of provision that transforms the pharmacy profession to be more accountable towards patient care, as opposed to drug production, ${ }^{4}$ and was supported by the US-Thai Consortium for the Development of Pharmacy Education. ${ }^{3}$ The big push came from an announcement of the Pharmacy
Council of Thailand (PCT) in 2008. It required that by the year 2014 only pharmacy graduates from the 6-year program with a minimum of 2,000 hours professional practice would be eligible for pharmacy licensure examination. ${ }^{3,5,6}$ This announcement is imperative for all pharmacy schools to change their curriculum. Thus, at the end of 2012, all of the 19 pharmacy schools changed their curriculum to the 6-year Pharm D program. ${ }^{7}$

In academic year 2012 (June 2012-March 2013), Thai pharmacy education was under such transition. It consisted of two undergraduate programs: the 5-year Bachelor of Science in Pharmacy (BSc) degree and the 6-year Pharm D degree. In the 5-year BSc program, there were two major tracks with different focuses, the Pharmaceutical Sciences (BScPsci), which is a product-oriented track, and the Pharmaceutical Care (BScPcare), which is a patient-oriented track. Students choose the major track in their third year and complete more specific courses and 500 hours of professional training based on their interest track in the fourth and fifth years. ${ }^{8}$

On the other hand, the traditional patient-focused 6-year Pharm D degree program placed more emphasis on clinical practices with medication therapy in individual patient. The additional year provides the sixth-year students with more experience gained through 6-7 clinical clerkships under the supervision of preceptors, mainly in hospitals and community pharmacies. ${ }^{9}$ Figure 1 shows major differences

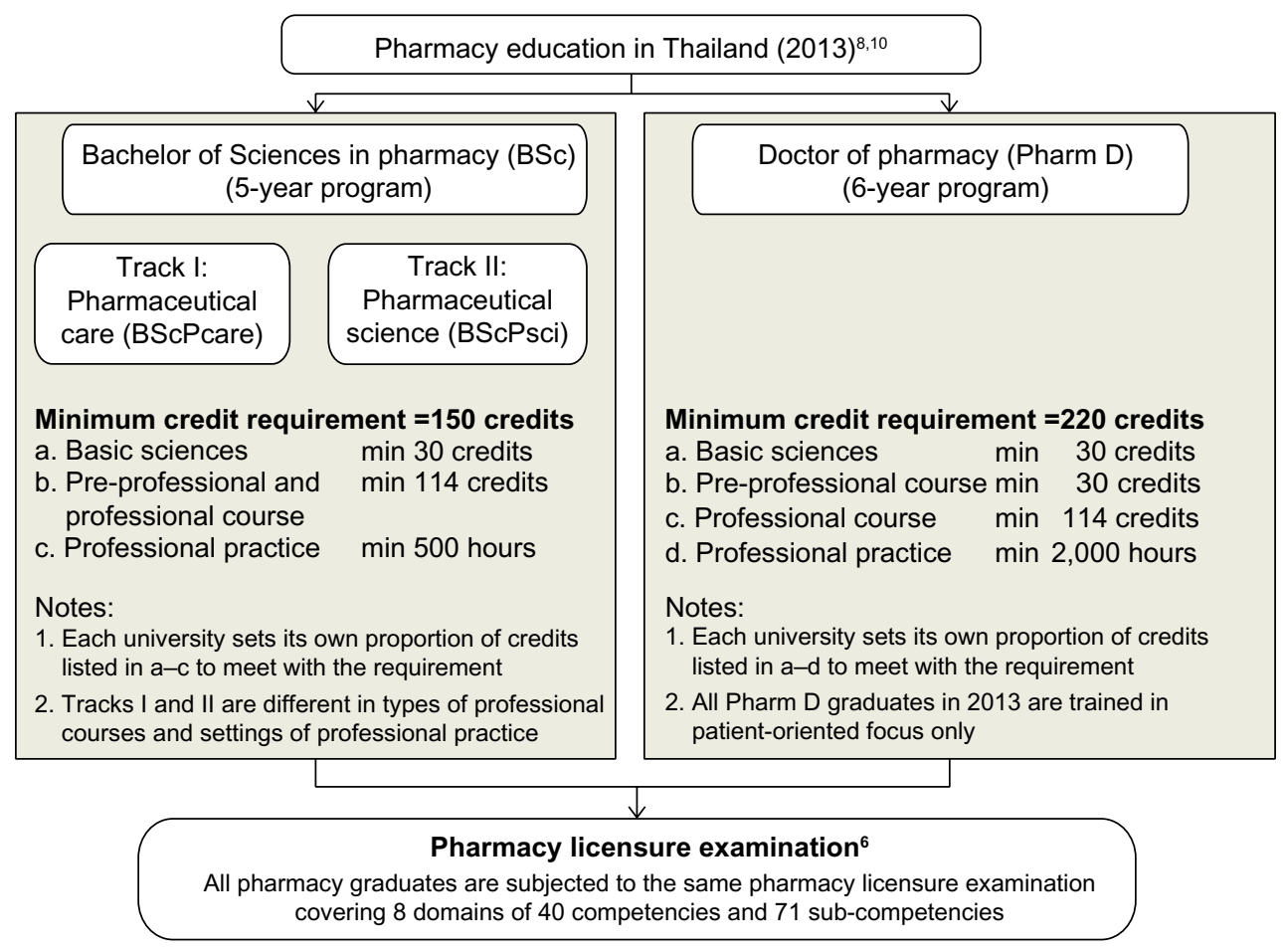

Figure I Comparison of required curriculum structure in 5-year BSc and 6-year Pharm D programs. 
in curriculum structure of the 5-year BSc and the 6-year Pharm D programs. ${ }^{8,10}$

It is important to note that pharmacy graduates from the Pharm D program in 2013 were trained in the traditional patient-focused 6-year Pharm D only. ${ }^{7}$ However, pharmacy education in Thailand still continues evolving in response to the needs of the health systems. Recently, two tracks of Pharm D have been proposed. One is pharmaceutical care-Pharm D, which is patient-oriented, and the other is pharmaceutical science-Pharm D (or industrial pharmacyPharm D) which is product-oriented. An additional track that has been discussed is social and administrative pharmacy (SAP)-Pharm D - though whether it should be independent or included in such two tracks of the Pharm D program is as yet unsettled. ${ }^{3}$

Despite the wide range of skills taught in the BSc and Pharm D programs, all pharmacy graduates need to pass the same competency licensure examination, regulated by the PCT. The eight domains of the pharmacy competency standards cover both the knowledge and skills in pharmaceutical care (eg, health assessment for patient counseling and referral, planning for rational drug use, follow-up and solving drug-related problems, and provide reliable health information), pharmaceutical sciences (eg, pharmaceutical compounding including extemporaneous preparation and quality assurance) and administrative pharmacy (eg, assessment of health problem and medication need in community, drug selection and procurement, and regulatory affairs) that students are required to master. ${ }^{6}$

Pharmacy graduates have choices to work in the public or private sectors. However, major health-care delivery is in the public sector and operated by the Ministry of Public Health (MOPH), as it has health facilities geographically distributed across the country. MOPH health facilities consist of 57 specialized hospitals located in Bangkok and cities in some provinces, 96 regional/provincial hospitals at the provincial level, 787 community hospitals at the district level, and 9,769 primary health care hospitals at the subdistrict level across the country. There are 133 public hospitals, operated by other public organizations as well such as military, universities, and local government organizations. ${ }^{11}$ For pharmaceutical regulatory affairs, pharmacists serve in 76 provincial health offices across the country as well as national regulatory agencies such as the Food and Drug Administration and other MOPH units. Pharmacists are distributed across the private sector including 326 private hospitals, ${ }^{11} 12,123$ pharmacies, 172 manufacturing plants, and 655 importation companies as well. ${ }^{12}$
A severe shortage of pharmacists in the public sector led to an initiative by the MOPH to launch a compulsory public service program in 1984. This program required new pharmacy graduates from public universities to work in a rural area for 2 years or otherwise to pay a penalty fee of US\$6,667. ${ }^{13}$ The program was successful in increasing the number of pharmacists in the public sector from $25 \%$ to $74.8 \%$ between 1983 and $1999 .{ }^{13}$ In 1998, the compulsory public service program was ended due to the 1997 economic crisis and the government's downsizing policy on the public workforce. ${ }^{3}$ The public service program for new pharmacy graduates was resumed in 2006 to replace about 350 position vacancies each year through the unilateral contract applied between the MOPH and pharmacy students. ${ }^{7}$ Under this contract, the MOPH will fill up vacant pharmacist posts in public institutes with new pharmacy graduates who enrolled in the public service program. There is no legal obligation for the MOPH to ensure that all pharmacy graduates enrolled in the public service program will get a position in the public settings, especially when the number of enrolled pharmacy graduates exceeds the number of vacant posts.

However, the public service program seems to be unable to provide an adequate supply of pharmacists for public health systems. Many MOPH hospitals still find themselves with an inadequate number of pharmacists. To cope with this problem, they hire pharmacists as temporary employees but are often unable to retain these pharmacists long term because such temporary positions provide no opportunities for career advancement or promotion for these pharmacists. ${ }^{14}$

In the 2013 public service program, a total of 350 pharmacist posts were available for new pharmacy graduates. These positions were allocated into four public settings with different proportions as follows: $56 \%$ of the posts are in community hospitals, $28 \%$ are in regional/provincial hospitals, $14 \%$ are in provincial health offices, and $2 \%$ are in teaching institutes under the Praboromarachanok Institute for Health Workforce Development. ${ }^{15}$

Pharmacy graduates who wish to work in these public institutes need different skills and competencies. Specifically, pharmacist posts in regional/provincial hospitals need clinically oriented competencies, whereas those in community hospitals need a combination of clinical competency for secondary care level, some health administration and some law and regulation, and community skills. Pharmacists in provincial health offices may require more regulatory affairs competencies and community skills and relatively less clinical ones.

To the best of our knowledge, some previous comparisons of professional competency were done between Thai 
medical graduates from different modes of admission, but not in pharmacy graduates. ${ }^{16,17}$ The purpose of this study was to compare perception of professional competency among pharmacy graduates from three different programs available in year 2013: Pharm D, BScPcare, and BScPsci who enrolled in the public service program. Our hypothesis was that pharmacy graduates with Pharm D (a 6-year program) may find themselves more clinically competent than those who graduated with a BSc, but would self-asses as less competent in regulatory affairs, including consumer protection and community health services, than the BSc graduates.

\section{Methods}

\section{Study design and target population}

A cross-sectional survey was conducted among the pharmacy graduates who enrolled in the public service program and attended Thailand's annual health worker meeting on April 2, 2013 for workplace selection. This meeting was jointly arranged by the MOPH and the health professional associations. It aimed to orientate new graduates from schools of medicine, dentistry, and pharmacy about choices of workplace, career paths, and further education opportunities. In this meeting, the pharmacy graduates needed to choose an MOPH-listed workplace to fill in vacant posts. In the case of oversubscription against vacant posts, the pharmacy graduates would draw lots to determine who went to what posts. ${ }^{18}$ Generally, remaining posts in the following rounds were in remote areas.

In 2013 , there was a total of 1,980 pharmacy graduates from all 19 universities. Around two-thirds (or 1,511 pharmacy graduates) were from 14 public universities. There were 536 out of 1,511 pharmacy graduates (or 33.5\%) enrolled in the public service program and participated in this meeting, ${ }^{7,15,19}$ and they serve as the target group of this study.

\section{Questionnaire design}

The survey used a self-administered, structured, closed-ended questionnaire to collect data. The questionnaire consisted of respondents' characteristics and perception of professional competencies.

The questions on respondents' characteristics included demographic information (eg, age and sex), location of hometown, location of pharmacy schools, type of pharmacy programs (ie, Pharm D, BScPcare, and BScPsci), and mode of admission (ie, national entrance examination, direct admission, special quota admission, or others). The special quota admission aims to recruit talent students (eg, outstanding academic and athletic abilities). The "others" mode of admission includes university initiatives to recruit specific groups of individuals in order to address the needs of health systems - for example, a rural pharmacist program recruiting rural students with an obligation to serve as rural pharmacists in their hometown or rural areas. Other examples are initiatives to recruit non-pharmacy college students or individuals with a college degree who wish to earn the pharmacy degree in pharmacy. However, the number of students recruiting via the "others" modes of admission is very small. Regardless of modes of admission, all pharmacy students are subjected to the same requirements under their programs.

Perception of professional competency was measured using a self-report. There were 13 items of professional competency (see Table S1). Responses were made on a 5-point Likert scale, ranging from " 1 " indicating least competent to " 5 " indicating most competent on each competency item.

To ensure face validity, the questionnaire was reviewed by three pharmacists who worked in a pharmacy school at a public university, a community hospital, and a drug regulatory agency. It is important to note that the questionnaire did not include product-oriented competency such as drug compounding and analysis because this competency is irrelevant to the needs of the MOPH vacant posts. To avoid a contamination effect, the questionnaire was pretested on fourth-year pharmacy students, as opposed to the fifth-year BSc and the sixth-year Pharm D students who would graduate in the year that our study was conducted and then become the targeted group of our study. The reliability test using Cronbach's alpha derived from the targeted group of this study was 0.92 .

\section{Data collection}

The data collection was conducted during Thailand's annual health worker meeting on April 2, 2013 for workplace selection of pharmacy graduates. The questionnaire was enclosed in a package of workplace registration documents. Upon receiving the package, the study goals and protocols were explained to each pharmacy graduate, as well as research ethical issues such as voluntary participation, anonymity, and information confidentiality. On average, a questionnaire took 10 minutes to be completed.

\section{Statistical analysis}

All statistical analyses were performed using SPSS version 18.0 (SPSS Inc., Chicago, IL, USA). Descriptive statistics were used to summarize demographic characteristics of pharmacy graduates, admission mode, type of pharmacy programs, location of pharmacy school, and location of hometown. Categorical variables are presented as number 
and percentage. Continuous variables are presented as mean and standard deviation, or median and range. Chi-square test or Fisher's exact test was performed on categorical variables across pharmacy programs. Kruskal-Wallis test was used to compare age differences across pharmacy programs. Oneway analysis of variance (ANOVA) with Bonferroni's post hoc test was used to identify differences in professional competency across pharmacy programs. The factor analysis with principal components analysis method with varimax rotation was used to categorize 13 items of professional competency into group domains, and a factor loading of 0.60 was used as a cutoff point. The mean differences of composite scores of each group domain across pharmacy programs were analyzed using one-way ANOVA. A $P$-value $<0.05$ was considered as statistically significant.

\section{Ethics approval}

While informed consent was sought, and protection of confidentiality was strictly followed, the National Ethical Review Committee waived ethical clearance as this is a regular monitoring work by the Government as shown in the letter Ref IHRP 47.2/2010 dated January 28, 2010.

\section{Results}

A total of 266 out of 536 pharmacy graduates attending the 2013 annual health worker meeting for workplace selection completed the questionnaires, accounting for the response rate of $49.6 \%$. The proportion of pharmacy graduates from Pharm D, BScPcare, and BScPsci was around onethird each.

\section{Respondents' characteristics}

Approximately two-thirds (77\%) of pharmacy graduates were female. Age ranged from 21 to 36 years, with the age median at 23 years in the BScPcare and BScPSci programs and 24 years in the Pharm D program. Most pharmacy graduates were recruited into the programs via the national entrance admission and direct admission. Approximately $27 \%$ of graduates were from the pharmacy schools located in the north and north-eastern regions, $24 \%$ in the south, and $22 \%$ in the central region. The majority of the Pharm D graduates were from the pharmacy school in the north and north-eastern regions. Most BScPcare graduates were from the pharmacy schools in central and north-eastern regions, whereas BScPSci graduates were mostly from the pharmacy schools in the south. The characteristics of pharmacy graduates are presented in Table 1 .

The univariate analysis showed that there were no statistically significant differences in sex and types of admission among the three groups of pharmacy graduates. However, age and the locations of pharmacy schools and of hometowns were statistically significantly different among the pharmacy programs $(P<0.001)$. Specifically, the age distribution in the BScPcare program shows a wider range of 22-36 years,

Table I Characteristics of pharmacy graduates in 2013

\begin{tabular}{|c|c|c|c|c|c|}
\hline \multirow[t]{2}{*}{ Attribute } & \multirow{2}{*}{$\begin{array}{l}\text { Total } \\
n=266\end{array}$} & \multicolumn{3}{|c|}{ Pharmacy programs } & \multirow[t]{2}{*}{$P$-value } \\
\hline & & $\begin{array}{l}\text { Pharm D } \\
n=93\end{array}$ & $\begin{array}{l}\text { BScPcare } \\
n=87\end{array}$ & $\begin{array}{l}\text { BScPsci } \\
n=86\end{array}$ & \\
\hline \multicolumn{6}{|l|}{ Demographic factors } \\
\hline Age median, years (range; min-max) & 266 & $24(23-26)$ & $23(22-36)$ & $23(2 I-26)$ & $<0.001$ \\
\hline Sex & & & & & 0.310 \\
\hline Female & 205 & $76(82 \%)$ & 67 (77\%) & $62(72 \%)$ & \\
\hline Male & 61 & 17 (I8\%) & $20(23 \%)$ & $24(28 \%)$ & \\
\hline Admission mode & & & & & 0.383 \\
\hline National entrance admission & 108 & 4 I (44\%) & $33(38 \%)$ & $34(39 \%)$ & \\
\hline Direct admission & 88 & $35(38 \%)$ & $28(32 \%)$ & $25(29 \%)$ & \\
\hline Special quota admission & 50 & 13 (I4\%) & 16 (19\%) & $21(24 \%)$ & \\
\hline Others & 19 & $4(4 \%)$ & $9(10 \%)$ & $6(7 \%)$ & \\
\hline Location of pharmacy school & & & & & $<0.001$ \\
\hline Bangkok and central & 59 & $9(10 \%)$ & $30(34 \%)$ & $20(23 \%)$ & \\
\hline North-eastern & 72 & $29(31 \%)$ & $33(38 \%)$ & $10(12 \%)$ & \\
\hline North & 71 & $43(46 \%)$ & II (I3\%) & $17(20 \%)$ & \\
\hline South & 64 & $12(13 \%)$ & $13(15 \%)$ & $39(45 \%)$ & \\
\hline Location of hometown & & & & & $<0.001$ \\
\hline Bangkok and central & 53 & $16(17 \%)$ & $22(25 \%)$ & 15 (I7\%) & \\
\hline North-eastern & 76 & $33(35 \%)$ & $31(36 \%)$ & $12(14 \%)$ & \\
\hline North & 68 & $33(35 \%)$ & 17 (19\%) & $18(21 \%)$ & \\
\hline South & 69 & II (I2\%) & 17 (19\%) & $4 \mathrm{I}(48 \%)$ & \\
\hline
\end{tabular}

Abbreviations: Pharm D, Doctor of Pharmacy; BSc, Bachelor of Sciences in Pharmacy; Psci, Pharmaceutical Science; Pcare, Pharmaceutical Care. 
compared with those of 21-26 years and 23-26 years in the BScPSci program and the Pharm D program, respectively.

\section{Professional competency perception}

Overall, pharmacy graduates across different programs perceived their professional competency to be between a moderate to a high level $(\min 3.24, \max 4.19$ from a 5-point scale; $1=$ least, and $5=$ most). Of 13 professional competencies, four competencies had no statistically significant differences across pharmacy programs. These competencies were competency in solving public health problems in rural areas, competency in health administration, competency in communicating with patients and lay people, and competency in inter-professional collaboration.

For the other nine competencies, there were statistically significant differences across pharmacy programs. These differences were also confirmed by Bonferroni's post hoc test. Compared with their peers in the other two programs, Pharm D graduates assessed themselves higher in three competencies: acute-care services $(P<0.001)$, medication-reconciliation services $(P<0.001)$, and primary-care services $(P=0.005)$. There were no significant differences between BScPcare and BScPsci graduates in these three areas. Pharm D graduates reported higher competency than BScPsci graduates in ambulatory-care services and patient-counseling services, and higher than BScPcare graduates in two items: drug use evaluation/drug utilization review, and drug information services. BScPsci graduates assessed themselves as more competent than those from the BScPcare program in the areas of consumer health protection and herbal and alternative medicines. Table 2 shows the comparison of professional competency perceptions across pharmacy programs.

The factor analysis with principal components method categorized the 13 items of professional competency into four group domains, explaining $73.4 \%$ of the total variance. The four group domains were patient care (five items), consumer protection and community health services (three items), health administration and communication (three items), and drug review and information (two items). The internal consistency for these four group domains is high, as Cronbach alpha values ranged from 0.74 to 0.88 . The results of factor analysis are presented in Table 3.

A comparison of composite scores of four competency domains indicated that there were statistically significant differences in three domains across pharmacy programs. These were patient care domain, consumer protection and community health services domain, and drug review and information domain $(P<0.001, P<0.001$, and $P=0.026$, respectively). No differences were observed in the health administration and communication domain among three pharmacy programs. Additionally, the results revealed that Pharm D graduates had higher mean composite scores in two domains: patient care domain and drug review and information domain. Pharmacy graduates from the BScPsci program had higher

Table 2 Comparison of professional competency perception across pharmacy programs

\begin{tabular}{|c|c|c|c|c|}
\hline \multirow[t]{2}{*}{ Competency domains and items } & \multicolumn{3}{|l|}{ Mean (SD) } & \multirow[t]{2}{*}{$P$-value } \\
\hline & Pharm D & BScPcare & BScPsci & \\
\hline \multicolumn{5}{|l|}{ Domain I: patient care } \\
\hline I. An inter-professional collaboration & $3.89(0.62)$ & $3.75(0.67)$ & $3.75(0.67)$ & 0.238 \\
\hline 2. Ambulatory care services & $4.19(0.63)^{\mathrm{a}}$ & $3.99(0.68)$ & $3.76(0.72)^{\mathrm{a}}$ & $<0.001$ \\
\hline 3. Acute care services & $3.90(0.77)^{\mathrm{a}, \mathrm{b}}$ & $3.57(0.77)^{\mathrm{b}}$ & $3.45(0.70)^{\mathrm{a}}$ & $<0.001$ \\
\hline 4. Patient counseling services on medication use & $4.19(0.65)^{\mathrm{a}}$ & $4.01(0.7 I)$ & $3.67(0.75)^{\mathrm{a}}$ & $<0.001$ \\
\hline 5. Medication reconciliation services & $3.98(0.74)^{a, b}$ & $3.70(0.79)^{b}$ & $3.47(0.70)^{\mathrm{a}}$ & $<0.001$ \\
\hline \multicolumn{5}{|l|}{ Domain 2: consumer protection and community health services } \\
\hline 6. Consumer health protection (eg, surveillance of health products) & $3.55(0.83)$ & $3.29(0.89)^{c}$ & $3.67(0.76)^{c}$ & 0.009 \\
\hline 7. Herbal and alternative medicines & $3.46(0.86)$ & $3.24(0.87)^{c}$ & $3.71(0.84)^{c}$ & 0.002 \\
\hline $\begin{array}{l}\text { 8. Primary care services (eg, patient home visit and supervision } \\
\text { of primary care hospitals) }\end{array}$ & $4.09(0.76)^{a, b}$ & $3.74(0.85)^{\mathrm{b}}$ & $3.78(0.7 \mathrm{I})^{\mathrm{a}}$ & 0.005 \\
\hline \multicolumn{5}{|l|}{ Domain 3: health administration and communication } \\
\hline 9. Solving public health problems in rural areas & $3.72(0.72)$ & $3.57(0.80)$ & $3.53(0.66)$ & 0.213 \\
\hline $\begin{array}{l}\text { 10. Health administration (eg, drug selection, procurement, } \\
\text { and inventory management) }\end{array}$ & $3.5 \mathrm{I}(0.76)$ & $3.30(0.85)$ & $3.40(0.74)$ & 0.197 \\
\hline II. Communication with patients and lay people & $4.09(0.7 I)$ & $3.93(0.83)$ & $3.85(0.68)$ & 0.094 \\
\hline \multicolumn{5}{|l|}{ Domain 4: drug review and information } \\
\hline 12. Drug use evaluation or drug utilization review & $3.73(0.74)^{\mathrm{b}}$ & $3.47(0.68)^{b}$ & $3.48(0.77)$ & 0.024 \\
\hline 13. Drug information services to health professionals and the public & $3.77(0.68)^{\mathrm{b}}$ & $3.46(0.76)^{b}$ & $3.66(0.72)$ & 0.013 \\
\hline
\end{tabular}

Notes: ${ }^{a}$ Difference between Pharm D and BScPSci programs; ${ }^{b}$ difference between Pharm D and BScPcare programs; ${ }^{c}$ difference between BScPcare and BScPSci programs. Abbreviations: Pharm D, Doctor of Pharmacy; BSc, Bachelor of Sciences in Pharmacy; Psci, Pharmaceutical Science; Pcare, Pharmaceutical Care; SD, standard deviation. 
Table 3 Factor analysis of professional competency perception

\begin{tabular}{|c|c|c|c|c|c|}
\hline \multirow{2}{*}{$\begin{array}{l}\text { Domain } \\
\text { Patient care }\end{array}$} & \multirow{2}{*}{$\begin{array}{l}\text { Variable } \\
\text { Ambulatory care services }\end{array}$} & \multicolumn{4}{|c|}{ Factor loading } \\
\hline & & $0.86 I$ & 0.094 & 0.184 & 0.173 \\
\hline & Inter-professional collaboration & 0.731 & 0.305 & 0.292 & 0.004 \\
\hline & Patient counseling on medication use & 0.719 & 0.104 & 0.165 & 0.392 \\
\hline & Acute care services & 0.665 & 0.074 & 0.100 & 0.527 \\
\hline & Medication reconciliation services & 0.590 & 0.170 & 0.230 & 0.488 \\
\hline $\begin{array}{l}\text { Consumer protection } \\
\text { and community health }\end{array}$ & $\begin{array}{l}\text { Consumer protection (eg, surveillance of health products, } \\
\text { pharmacies, and clinics) }\end{array}$ & 0.120 & 0.863 & 0.198 & 0.176 \\
\hline \multirow[t]{2}{*}{ services } & Herbal and alternative medicines & 0.123 & 0.726 & 0.270 & 0.280 \\
\hline & $\begin{array}{l}\text { Primary care services (eg, patient home visit and supervision } \\
\text { of primary care hospitals) }\end{array}$ & 0.520 & 0.601 & 0.186 & 0.208 \\
\hline Health administration & Solving public health problems in rural areas & 0.303 & 0.161 & 0.796 & 0.189 \\
\hline \multirow[t]{2}{*}{ and communication } & $\begin{array}{l}\text { Health administration (eg, drug selection, procurement, } \\
\text { and inventory management) }\end{array}$ & 0.050 & 0.355 & 0.745 & 0.183 \\
\hline & Communication with patients and lay people & 0.451 & 0.166 & 0.658 & 0.197 \\
\hline Drug review & Drug use evaluation or drug utilization review & 0.220 & 0.364 & 0.214 & 0.732 \\
\hline and information & Drug information services to health professionals and the public & 0.263 & 0.261 & 0.243 & 0.708 \\
\hline
\end{tabular}

Notes: Values in bold represent strong correlation to specific factors. Factor analysis was based on the principal components analysis method with varimax rotation. A factor loading of 0.60 was used as a cutoff point.

mean composite scores in the consumer protection and community health services domain. Figure 2 illustrates the comparison of mean composite scores of professional competency across pharmacy programs.

\section{Discussion}

A total of 266 pharmacy graduates completed the questionnaires, accounting for $49.6 \%$ of all pharmacy graduates enrolled in the public service program and $13.5 \%$ of the total pharmacy graduates in 2013. Although the respondents of 266 represent a small portion of total pharmacy graduates in 2013, they are the biggest group of new pharmacists entering to the public health settings around Thailand. The overall demographic characteristics of pharmacy graduates from this study are similar to those who graduated in previous years. ${ }^{18}$
No differences in sex and admission modes were observed across the three pharmacy programs.

The age distribution of BScPcare graduates was wider than the other two groups, because around $50 \%$ of students (four out of nine students) admitted via the "others" mode of admission in the BScPcare program were those who had already graduated with a degree in other areas or had been transferred from other science programs. The age range of these students was 26-36 years, which was higher than the BScPsci and Pharm D students being admitted via the "others" mode of admission as well.

Our study revealed that pharmacists with a Pharm D degree mostly graduated in the northern and north-eastern regions, and those with a BScPcare degree were concentrated in the central and north-eastern regions. In the southern

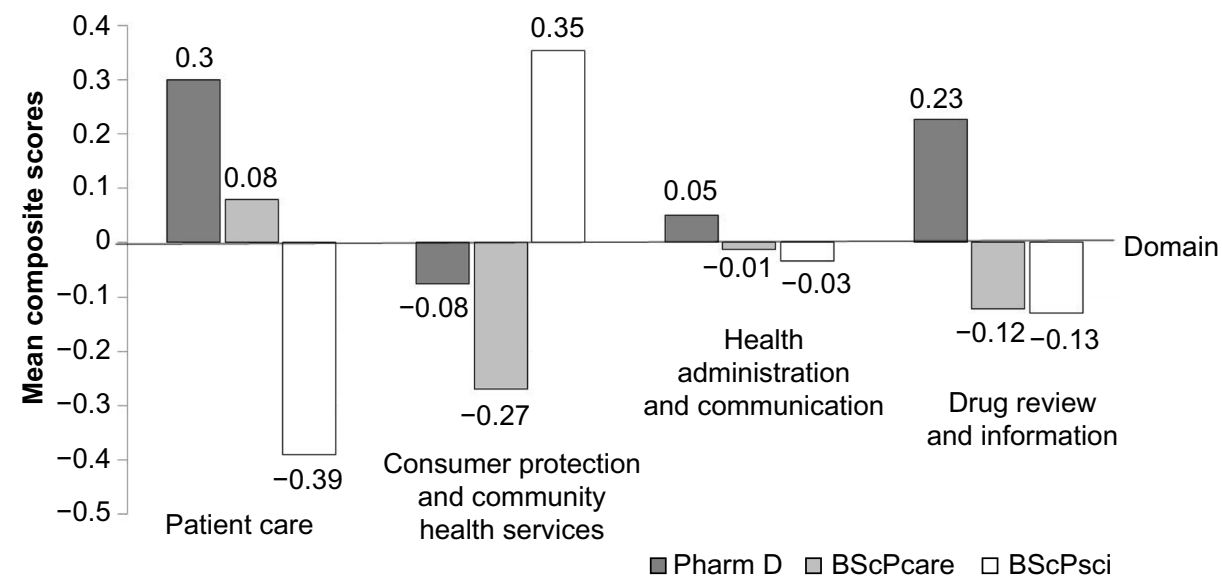

Figure 2 Comparison of mean composite scores of professional competency across pharmacy programs.

Abbreviations: Pharm D, Doctor of Pharmacy, BSc, Bachelor of Sciences in Pharmacy; Psci, Pharmaceutical Science; Pcare, Pharmaceutical Care. 
region, a higher number of pharmacy students graduated with a BScPsci degree. These expertise variations among new pharmacy graduates across regions are mainly due to two intertwined factors: the availability of different pharmacy programs in each region and the students' preference to study and work closely to their hometown. It is expected that these expertise variations across regions will disappear as pharmacy education is completely transformed into a 6-year Pharm D program for all pharmacy schools in 2014. This also means that students who graduated from the BScPcare and BScPsci programs in 2013 are the last batch of a 5-year bachelor's degree of sciences in pharmacy in most schools. This creates a gap in the pharmacy workforce (ie, the number of pharmacy graduates will decrease by half in 2014 because pharmacy graduates from 12 out of a total of 19 pharmacy schools are still in the pipeline of Pharm D program). ${ }^{7}$

Our study investigated differing perceptions of professional competency of pharmacy graduates from three different pharmacy programs: Pharm D, BScPcare, and BScPsci programs. Overall, we found that Pharm D graduates reported a positive competency in the patient care domain and the drug review and information domain, compared with their peers from BScPcare and BScPsci programs. This might be due to the patient-oriented nature of the Pharm D program. It is interesting to note that although graduates from the BScPcare program (which is also patient-oriented) also demonstrated positive competency in the patient care domain, their perception of their patient care competency is less positive than that of Pharm D program. This may be explained in the light of the number of professional practice average course credits. Specifically, Pharm D program had higher professional practice average course credits than that of the BSc programs (Figure 1). ${ }^{6,20}$ On the other hand, the BScPsci graduates had better competency in consumer protection (including regulatory affairs on health products and practice of pharmacies and clinics) and in herbal and alternative medicines. This finding is consistent with the nature of the BScPsci program, which is more product-oriented. ${ }^{20}$

Overall, pharmacy graduates seem to be confident in their competencies. This result agrees with a previous survey in 2012 , where $68.4 \%$ of pharmacy students had positive attitudes towards how well their curriculum prepared them to work in rural areas, and the percentage was higher for pharmacy graduates than for medical $(56.0 \%)$ or dental $(52.0 \%)$ graduates. ${ }^{21}$ Pharmacy graduates from all three programs were most confident in their ability to communicate with patients and lay people, but less confident in their health administration. This observed result is similar to some other previous studies in pharmacy graduates ${ }^{22,23}$ and medical graduates ${ }^{17}$ and may reflect the current content ratio in Thai pharmacy schools, which was 2.1:2.9:1.0 (or 2:3:1) for patient-oriented, product-oriented, and SAP-oriented areas. ${ }^{20}$ Factors contributing to this phenomenon may include less credit hours allocated to courses related to administration skills, limitation of professional practice in this field due to some restriction related to law/regulation, and a lack of existing systematic training in the field of administrative pharmacy. A recent collaboration between many pharmacy schools to develop a new clerkship in hospital drug system management should help prepare pharmacy graduates in the next 1-2 years, and should be tested in the next survey. Regarding communication skills, adding courses for advocacy competency ${ }^{24}$ and professional communication for collaborative practice ${ }^{22}$ to a pharmacy training program would help prepare graduates for more effective communication with different stakeholders in the fast-moving health system.

Despite the existence of many courses on pharmacognosy and Thai herbal medicines available in the national essential list of medicines, Pharm D and BScPcare graduates were also less confident in terms of herbal and alternative medicines and consumer protection. This may be due to the fact that students were more exposed to chemicals and Western medicine products during their professional courses, and consumer protection-related skills are usually provided only as a lecture topic or as an elective course in some schools. However, since more (illegal) herbal and pharmaceutical products have been promoted through community radios, websites, and direct sales, new pharmacy graduates may need to keep up to date and prepare themselves for these challenges.

The traditional 6-year Pharm D program, which is primarily patient-oriented, ${ }^{3}$ has been adjusted to meet with the health systems and contexts in Thailand. A proposal to divide the Pharm D program into two tracks of patientoriented and product-oriented has been implemented in some universities, ${ }^{7}$ and a new track on SAP for PharmD program is under discussion. This reflects that pharmacy education in Thailand still continues changing and evolving. Thus, an annual survey of new pharmacy graduates should be continued to monitor changes of professional competency across different tracks of the Pharm D program. Longitudinal monitoring of these competencies in the same graduate cohort would be interesting, to see whether graduates get the appropriate position that fit to their trained competency or not. Additionally, as the roles of pharmacists in health systems are expanded, ${ }^{25}$ 
future studies should cover all pharmacy students in both public and private pharmacy schools, regardless of enrolment in public service programs. Some product-oriented competencies (eg, extemporaneous preparation for pediatric patients) should also be added to future questionnaires as well, to cover all possible responsibilities of hospital pharmacists.

The limitation of our study may come from the sampling frame and competency data collection. First, respondents in this study did not represent all pharmacy students graduating in 2013. Only pharmacy graduates who were enrolled in the public service program provided an eligible sample for this study. Pharmacy graduates from private universities and pharmacy graduates from public university who did not enroll in the public service program are not included in this study. Second, although there might be discrepancies between perceived and actual competence among pharmacy students, ${ }^{26-28}$ evidence suggests positive relationships between individuals' perceived ability/competency and their performance as well. ${ }^{29,30}$ Thus, while using self-reported perception of professional competency as a proxy measure for professional performance, future study may consider investigating and comparing self-assessment of professional competency and the objectively measured competence such as license examination scores and investigating relationships between perceived/actual professional competency and professional performance. Third, apart from the pharmacy programs, pharmacy school reputation and/or ranking might be a contributing factor for differences in perception of professional competency as well. Finally, a final year student survey would be an option to increase representativeness.

\section{Acknowledgments}

This is a collaborative study conducted by the International Health Policy Programme (IHPP) and Praboromarajchanok Institute for Health Workforce Development of the MOPH. Contribution by all pharmacy graduates who participated in the survey are recognized and appreciated. The authors thank Associate Professor Petcharat Pongcharoensuk for her constructive comments that helped improve the manuscript.

\section{Authors contributions}

WP and TW designed the study. NS and SS reviewed the literature and designed questionnaire. TW collected the data. SH and NS performed the data analysis. All authors contributed to drafting, revising, and approving the final version of this manuscript.

\section{Disclosure}

The authors declare that they have no competing interests.

\section{References}

1. International Pharmaceutical Federation (FIP). The 2012 FIP Global Pharmacy Workforce Report. Hague, The Netherlands: International Pharmaceutical Federation (FIP); 2012.

2. Nawanopparatsakul S, Keokitichai S, Wiyakarn S, Chantaraskul C. Challenges of pharmacy education in Thailand. Silpakorn Univ Int J. 2009-2010;9-10:19-39.

3. Pongcharoensuk P, Prakongpan S. Centennial pharmacy education in Thailand. J Asian Assoc Schools Pharm. 2012;1(1):8-15.

4. Hepler C, Strand L. Opportunities and responsibilities in pharmaceutical care. Am J Health Syst Pharm. 1990;47(3):533-543.

5. Chanakit T. Stakeholders' Perspectives on the Curriculum Changing to a Six Year Doctor of Pharmacy (PharmD) Programme in Thailand [proposal]. School of Pharmacy: Division of Social Research in Medicines and Health, School of Pharmacy, University of Nottingham; 2013.

6. Pharmacy Council of Thailand. Handbook of Pharmacy Profession Competencies, Pharmacy Council. Bangkok: Pharmacy Council Thailand; 2011. Available from: http://plecenter.org/share/file/file_134. pdf. Accessed September 17, 2014. Thai.

7. Subcommittee on Pharmacy Education, The Pharmacy Education Consortium of Thailand (PECT). Past ... Present ... Future of Pharmacy Education in Thailand. Paper presented at: The Thai Pharmacy Assembly Conference on the occasion of centennial celebration of pharmacy profession and pharmacy education in Thailand; January 10-12, 2014, 2013; Faculty of Pharmaceutical Sciences, Chulalongkorn University, Bangkok, Thailand.

8. Pharmacy Council of Thailand. Pharmacy Council Announcement No 12/2008: Accreditation criteria for Faculty of Pharmacy and pharmacy curriculum. In: Pharmacy Council, editor. Ministry of Public Health, Nonthaburee; 2008. Available from: http://pharmacycouncil. org/share/file/file_258.pdf. Accessed September 17, 2014. Thai.

9. Pharmacy Council of Thailand. Pharmacy Council Announcement No 26/2011: Pharmacy preceptor standard by Pharmacy Council Subcommittee on pharmacy education. In: Pharmacy Council, editor. Bangkok; 2011.

10. Office of the Higher Education Commission. Curriculum standard for undergraduate programs 2005. In: Ministry of Education Thailand, editor; 2005:7-13. Available from: http://www.mua.go.th/users/bhes/ catalog_h/StdEdu/LawBse/03.PDF. Accessed September 17, 2014. Thai.

11. Bureau of Policy and Strategy, Ministry of Public Health, Thailand. Number and types of health care facilities. Available from: http://203.157.10.8/hcode/query_02.php. Accessed June 16, 2014.

12. Bureau of Drug Control, Food and Drug Administration, Thailand. Number and types of pharmaceutical licenses in Thailand. Available from: http://drug.fda.moph.go.th/zone_search/files/sea001_d18.asp. Accessed June 16, 2014.

13. Wibulpolprasert S. Thailand Health Profile 2008-2010. Bangkok: WVO Office of Printing Mill, War Veterans Organization of Thailand; 2011.

14. Prapunwattana M. Proceeding of Thailand pharmacy professional assembly (99 years). Paper presented at: Thailand Pharmacy Professional Assembly (99 years), 2012.

15. Ministry of Public Health Thailand. Position assignment for contracting pharmacy graduates 2013. Ministry of Public Health Thailand; 2013.

16. Putthasri W, Suphanchaimat R, Topothai T, Wisaijohn T, Thammatacharee N, Tangcharoensathien V. Thailand special recruitment track of medical students: a series of annual cross-sectional surveys on the new graduates between 2010 and 2012. Hum Resour Health. 2013;11:47. 
17. Suphanchaimat R, Topothai T, Thaichinda C, et al. Newly medical graduates' confidence in medical and public-health competency: exploratory factor analysis and multiple regression. J Health Syst Res. 2012;6(4):1-12.

18. Thammatacharee N, Suphanchaimat R, Wisaijohn T, Limwattananon S, Putthasri W. Attitudes toward working in rural areas of Thai medical, dental and pharmacy new graduates in 2012: a cross-sectional survey. Hum Resour Health. 2013;11:53.

19. Ministry of Public Health Thailand. List of contracting pharmacy graduates 2013 eligible for Thai Ministry of Public Health's annual health worker meeting 2013.

20. Kapol N, Maitreemit P, Pongcharoensuk P, Armstrong EP. Evaluation of curricula content based on Thai pharmacy competency standards. Am J Pharm Educ. 2008;72(1):9.

21. Wisaijohn T, Thammatacharee N, Suphanchaimat R, Pudpong N, Putthasri W. Factors and attitudes related to the decision of doctors, dentists, and pharmacists who graduated in 2012 to practice in rural areas. J Health Sci. 2013;22(4):596-607.

22. Nochaiwong S, Lucksiri A, Leungsopapan T. Pharmacy Students Satisfaction Toward the Doctor of Pharmacy Program (Pharm D) and their Attitudes Toward the Works in Pharmaceutical Care. Chiang Mai: Faculty of Pharmacy, Chiang Mai University; 2011.

23. Scott DM, Friesner DL, Miller DR. Pharmacy students' perceptions of their preparedness to provide pharmaceutical care. Am J Pharm Educ. 2010;74(1):8.
24. Bzowyckyj AS, Janke KK. A consensus definition and core competencies for being an advocate for pharmacy. Am J Pharm Educ. 2013;77(2):24.

25. The Pharmacy Education Consortium of Thailand (PECT). Role of pharmacist in Thai society in the second century. Paper presented at: The Thai Pharmacy Assembly Conference on the occasion of centennial celebration of pharmacy profession and pharmacy education in Thailand; January 10-12, 2014, 2013; Faculty of Pharmaceutical Sciences, Chulalongkorn University, Bangkok, Thailand.

26. Austin Z, Gregory PA. Evaluating the accuracy of pharmacy students' self-assessment skills. Am J Pharm Educ. 2007;71(5):89.

27. Motycka CA, Rose RL, Ried LD, Brazeau G. Self-assessment in pharmacy and health science education and professional practice. Am J Pharm Educ. 2010;74(5):85.

28. Naughton CA, Friesner DL. Comparison of pharmacy students' perceived and actual knowledge using the Pharmacy Curricular Outcomes Assessment. Am J Pharm Educ. 2012;76(4):63.

29. Bandura A. Self-Efficacy: The Exercise of Control. New York: W.H.Freeman; 1997.

30. Chamorro-Premuzic T, Harlaar N, Greven CU, Plomin R. More than just IQ: A longitudinal examination of self-perceived abilities as predictors of academic performance in a large sample of UK twins. Intelligence. 2010;38:385-392. 


\section{Supplementary material}

Table SI Please assess your competency on these following items

\begin{tabular}{|c|c|c|c|c|c|c|}
\hline \multirow[t]{2}{*}{ No } & \multirow[t]{2}{*}{ Items } & \multicolumn{5}{|c|}{ Least --------------- Most } \\
\hline & & $\mathbf{I}$ & 2 & 3 & 4 & 5 \\
\hline I & Solving public health problems in rural areas & & & & & \\
\hline 2 & Conducting health administration eg, drug selection, procurement and inventory management & & & & & \\
\hline 3 & Communicating with patients and lay people & & & & & \\
\hline 4 & Collaborating with an inter-professional health team & & & & & \\
\hline 5 & Providing pharmaceutical care in ambulatory care services & & & & & \\
\hline 6 & Providing pharmaceutical care in acute care services & & & & & \\
\hline 7 & $\begin{array}{l}\text { Providing counseling services for patients regarding self-care and medication use eg, warfarin clinic, } \\
\text { tuberculosis clinic and diabetes clinic }\end{array}$ & & & & & \\
\hline 8 & Providing medication reconciliation services & & & & & \\
\hline 9 & Using herbal and alternative medicines & & & & & \\
\hline 10 & Conducting drug use evaluation or drug utilization review & & & & & \\
\hline 11 & Providing drug information services to health professionals and the public & & & & & \\
\hline 12 & $\begin{array}{l}\text { Working with primary care settings eg, home visit of patients with chronic condition and supervision } \\
\text { of primary care hospitals }\end{array}$ & & & & & \\
\hline 13 & $\begin{array}{l}\text { Ensuring consumer health protection eg, surveillance of health products in communities regarding their } \\
\text { quality, labelling and advertising; and surveillance of pharmacies and clinics regarding law compliance }\end{array}$ & & & & & \\
\hline
\end{tabular}

Advances in Medical Education and Practice

Dovepress

\section{Publish your work in this journal}

Advances in Medical Education and Practice is an international, peerreviewed, open access journal that aims to present and publish research on Medical Education covering medical, dental, nursing and allied health care professional education. The journal covers undergraduate education, postgraduate training and continuing medical education including emerging trends and innovative models linking education, research, and health care services. The manuscript management system is completely online and includes a very quick and fair peer-review system. Visit http://www.dovepress.com/testimonials.php to read real quotes from published authors.

Submit your manuscript here: http://www.dovepress.com/advances-in-medical-education-and-practice-journal 